\title{
Coupled solutions for a bivariate weakly nonexpansive operator by iterations
}

\author{
Vasile Berinde ${ }^{1 *}$, Abdul Rahim Khan² and Madalina Păcurar ${ }^{3}$
}

\section{"Correspondence:}

vasile_berinde@yahoo.com

'Department of Mathematics and

Computer Science, North University

Center at Baia Mare, Technical

University of Cluj-Napoca,

Victorie 76, Baia Mare, 430072, Romania

Full list of author information is available at the end of the article

\begin{abstract}
We prove weak and strong convergence theorems for a double Krasnoselskij-type iterative method to approximate coupled solutions of a bivariate nonexpansive operator $F: C \times C \rightarrow C$, where $C$ is a nonempty closed and convex subset of a Hilbert space. The new convergence theorems generalize, extend, improve, and complement very important old and recent results in coupled fixed point theory. Some appropriate examples to illustrate our new results and their generalization are also given.
\end{abstract}

\section{Introduction and preliminaries}

Let $X$ be a nonempty set. A pair $(x, y) \in X \times X$ is called a coupled fixed point of the mapping $F: X \times X \rightarrow X$ if it is a solution of the system

$$
F(x, y)=x, \quad F(y, x)=y \text {. }
$$

The study of coupled fixed points has been considered in 2006 by Bhaskar and Lakshmikantham [1] (see also [2]). A rich literature on the existence of coupled fixed points of mixed monotone, monotone and non-monotone mappings, has been developed ever since the publication of that paper (see [3-30]).

The novelty of this paper is that it considers coupled fixed point problem in a partially ordered metric space for mixed monotone mapping $F: X \times X \rightarrow X$ in conjunction with a contraction-type condition of the form

$$
d(F(x, y), F(u, v)) \leq \frac{k}{2}[d(x, u)+d(y, v)], \quad \text { for each } x \geq u, y \leq v
$$

where $k \in[0,1)$.

In particular, the authors establish three kinds of coupled fixed point results: (1) existence theorems (Theorems 2.1 and 2.2); (2) an existence and uniqueness theorem (Theorem 2.4); and (3) theorems that ensure the equality of the coupled fixed point components (Theorems 2.5 and 2.6).

Theorem 1 ([1], Theorem 2.1 and Theorem 2.6) Let $(X, \leq)$ be a partially ordered set and suppose there is a metric $d$ on $X$ such that $(X, d)$ is a complete metric space. Let $F: X \times X \rightarrow$ $X$ be a continuous mapping having the mixed monotone property on $X$.

(02014 Berinde et al.; licensee Springer. This is an Open Access article distributed under the terms of the Creative Commons Attribution License (http://creativecommons.org/licenses/by/2.0), which permits unrestricted use, distribution, and reproduction in any medium, provided the original work is properly cited. 
If F satisfies (1.1) and there exist $x_{0}, y_{0} \in X$ such that

$$
x_{0} \leq F\left(x_{0}, y_{0}\right) \quad \text { and } \quad y_{0} \geq F\left(y_{0}, x_{0}\right)
$$

then there exist $\bar{x}, \bar{y} \in X$ such that

$$
\bar{x}=F(\bar{x}, \bar{y}) \quad \text { and } \quad \bar{y}=F(\bar{y}, \bar{x}) .
$$

Suppose, additionally, that $x_{0}, y_{0} \in X$ are comparable. Then for the coupled fixed point $(\bar{x}, \bar{y})$, we have $\bar{x}=\bar{y}$.

Contraction-type conditions arise naturally in connection with Lipshitzian properties of mappings in the study of nonlinear functional differential and integral equations. Therefore, coupled fixed point results for contractions have important applications in nonlinear analysis and have been applied successfully for solving various classes of nonlinear functional equations: integral equations and systems of integral equations $[5,7,13,17,18,26$, $27,31]$; (periodic) two point boundary value problems [1, 10, 15, 28]; nonlinear Hammerstein integral equations [25]; nonlinear elliptic problems and delayed hematopoesis models [29]; systems of differential and integral equations [30]; nonlinear matrix and nonlinear quadratic equations $[4,13]$, initial value problems for ODE [6, 24], etc.

We note that in all the above mentioned cases, the main conclusion is drawn using ([1], Theorem 2.6), which guarantees existence as well as equality of components of the coupled fixed point.

On the other hand, in almost all the papers dealing with study of coupled fixed points, no attention is paid to the constructive features of such a result, i.e., there is neither explicit mention of the method by which one could approximate that coupled fixed point, nor on the order of convergence and/or error estimates of the iteration processes involved.

Moreover, there exist (mixed) monotone mappings $F(x, y)$ (see Examples 1 and 3 below), which possess coupled fixed points, for which no coupled fixed point theorem existing in literature can be applied. This is mainly because all those theorems (we refer here only to the ones given in $[1,4-7,10,13,15-18,23-31])$ are based on a strict contractive-type condition (1.1).

All the above observations motivate for constructive study of coupled fixed points of a bivariate mapping $F: X \times X \rightarrow X$ satisfying a weaker contractive condition of nonexpansiveness type and providing a constructive method to approximate these coupled fixed points, which we generally meet in applications, i.e., when we have equality of the coupled fixed point components.

The only paper that considers asymptotically nonexpansive bivariate mappings and the existence of their coupled fixed points is due to Olaoluwa et al. [22]. No other attempt has been made to tackle this important problem. We find here coupled solutions for a bivariate weakly nonexpansive operator on Hilbert spaces through an iterative method. Since nonexpansive bivariate mappings are particular sub-classes of the weakly nonexpansive mappings considered in the present paper, our results also generalize, improve and complement the corresponding results obtained in [22].

In order to illustrate the broader scope and novelty of our results, we present appropriate examples to delineate them from the existing coupled fixed point theorems in literature and indicate their potential use in applications. 


\section{Nonexpansive bivariate operators}

In this paper, we define the concept of nonexpansiveness for bivariate mappings as follows.

Definition 1 Let $X$ be a normed linear space and $C$ be a subset of $X$. A mapping $F: C \times$ $C \rightarrow X$ is called weakly nonexpansive if

$$
\|F(x, y)-F(u, v)\| \leq a\|x-u\|+b\|y-v\|,
$$

for all $x, y, u, v \in C$, where $a, b \geq 0$ and $a+b \leq 1$.

A similar but stronger concept has been introduced in [22].

Definition 2 ([22]) Let $X$ be a normed linear space and $C$ be a subset of $X$. A mapping $F: C \times C \rightarrow X$ is called nonexpansive if

$$
\|F(x, y)-F(u, v)\| \leq \frac{1}{2}(\|x-u\|+\|y-v\|),
$$

for all $x, y, u, v \in C$.

Note that our condition (2.1) is more general than (2.2): any nonexpansive mapping $F$ is weakly nonexpansive but the converse is not true, in general, as shown below.

Example 1 Let $X=\mathbb{R}$ (with the usual metric) and $F: X^{2} \rightarrow X$ be defined by

$$
F(x, y)=\frac{x-2 y}{3}, \quad \forall x, y \in X
$$

Then $F$ satisfies condition (2.1) but does not satisfy condition (2.2). Moreover, $F$ possesses a unique coupled fixed point of the form $(x, x)$, i.e., $(0,0)$, but no coupled fixed point theorem established in $[1,4-7,10,13,15-18,23-31]$ (and in other related papers) can be applied to this function $F$.

First, let us note that (2.1) holds with the constants $a=\frac{1}{3}$ and $b=\frac{2}{3}$. Suppose $F$ satisfies (2.2).

Then, taking $x=y, y \neq z$ in (2.2), we get $\frac{1}{2} \geq \frac{2}{3}$, a contradiction. This proves that, indeed, $F$ does not satisfy (2.2).

To prove the last part of our claim, let us consider the contraction condition in [23] (the same is valid for the corresponding conditions in $[1,4-7,10,13,15-18,24-31])$,

$$
d(F(x, y), F(u, v)) \leq k d(x, u)+l d(y, v)
$$

where $k, l \in(0,1)$ with $k+l<1$.

Assume now that $F$ satisfies (2.3). Then, taking $x=u, y \neq z$ in (2.3), we get $l \geq \frac{2}{3}$ and taking $x \neq u, y=v$ in (2.3), we get $k \geq \frac{1}{3}$. Now these calculations for $k$ and $l$ lead to

$$
1 \leq k+l<1
$$

a contradiction. This proves that, indeed, $F$ does not satisfy the strict contraction condition (2.3). This is also true for contractive conditions considered in $[1,4-7,10,13,15-18$, 23-31]. 
Observe that for $F$ in this example, the double sequence $\left\{\left(x_{n}, y_{n}\right)\right\}_{n \geq 0}$, defined by the Picard-type iteration

$$
x_{n+1}=F\left(x_{n}, y_{n}\right), \quad y_{n+1}=F\left(y_{n}, x_{n}\right), \quad n \geq 0,
$$

with $x_{0}, y_{0} \in X$, is convergent and its limit is always a coupled fixed point of $F$ (but only in the case $x_{0}=y_{0}$ this coupled fixed point is $(0,0)$ ); a fact which follows immediately from the expressions of $x_{n}$ and $y_{n}$ :

$$
\begin{array}{ll}
x_{n}=\frac{1}{2}\left[x_{0}-y_{0}+\left(-\frac{1}{3}\right)^{n}\left(x_{0}+y_{0}\right)\right], & n \geq 0, \\
y_{n}=\frac{1}{2}\left[y_{0}-x_{0}+\left(-\frac{1}{3}\right)^{n}\left(x_{0}+y_{0}\right)\right], & n \geq 0 .
\end{array}
$$

It is important to note that Opoitsev [2] was the first who studied coupled fixed points of bivariate mappings (see also [32, 33]) where a double Picard-type iteration sequence $\left\{\left(x_{n}, y_{n}\right)\right\}_{n \geq 0}$ of the form (2.4) was used.

In order to state our main results, we need some concepts and results, adapted from the case of mono-variate operators to the case of bivariate operators.

The concept of demicompact operator has been introduced by Petryshyn [34] (see also [35] and [36]) for a mapping $T: C \rightarrow H$, where $C$ is a subset of a Hilbert space $H$. For the bivariate case it is adapted as follows.

Definition 3 A mapping $F: C \times C \rightarrow H$ is called demicompact if it has the property that whenever $\left\{u_{n}\right\}$ and $\left\{v_{n}\right\}$ are bounded sequences in $C$ with the property that $\left\{F\left(u_{n}, v_{n}\right)-u_{n}\right\}$ and $\left\{F\left(v_{n}, u_{n}\right)-v_{n}\right\}$ converge strongly to 0 , then there exists a subsequence $\left\{\left(u_{n_{k}}, v_{n_{k}}\right)\right\}$ of $\left\{\left(u_{n}, v_{n}\right)\right\}$ such that $u_{n_{k}} \rightarrow u$ and $v_{n_{k}} \rightarrow v$ strongly.

We need the following version of the well-known Browder-Gohde-Kirk fixed point theorem (see, for example, Theorem 3.1 in [37]), stated here in the Hilbert space setting.

Theorem 2 Let $C$ be a bounded, closed and convex subset of a Hilbert space $H$ and let $F: C \times C \rightarrow C$ be a (weakly) nonexpansive operator. Then $F$ has at least one coupled fixed point in $C$.

Proof Let $T: C \rightarrow C$ be given by $T(x)=F(x, x), x \in C$. By the (weakly) nonexpansiveness property of $F$, we obtain the nonexpansiveness of $T$ and hence, by the Browder-GohdeKirk fixed point theorem, it follows that $\operatorname{Fix}(T) \neq \emptyset$.

Remark 1 Theorem 2 shows that $F$ has at least one (coupled) fixed point of the form $(\bar{x}, \bar{x}) \in C \times C$, but, in general, for a bivariate mapping $F$ it is also possible to have coupled fixed points $(\bar{x}, \bar{y})$ with unequal components, i.e., such that $\bar{x} \neq \bar{y}$, as shown by the following example.

Example 2 Let $X=\mathbb{R}$ (with the usual metric), $C=[-4,4]$ and $F: C^{2} \rightarrow X$ be defined by

$$
F(x, y)=4-x^{2}-2 y, \quad \forall x, y \in C .
$$


Then $F$ is weakly Lipschitzian with constants $a=8$ and $b=2$ (in the sense of Definition 1 ) and $F$ possesses two coupled fixed points $(-4,-4),(1,1)$ with equal components and two coupled fixed points with unequal components, $(-1,2)$ and $(2,-1)$.

\section{Main results}

The main result of this paper is the following strong convergence theorem for a double Krasnoselskij-type algorithm associated with bivariate weakly nonexpansive operators on Hilbert spaces.

Theorem 3 Let $C$ be a bounded, closed and convex subset of a Hilbert space $H$ and let $F: C \times C \rightarrow C$ be weakly nonexpansive and demicompact operator. Then the set of coupled fixed points of $F$ is nonempty and the double iterative algorithm $\left\{\left(x_{n}, x_{n}\right)\right\}_{n=0}^{\infty}$ given by $x_{0}$ in $C$ and

$$
x_{n+1}=\lambda x_{n}+(1-\lambda) F\left(x_{n}, x_{n}\right), \quad n \geq 0,
$$

where $\lambda \in(0,1)$, converges (strongly) to a coupled fixed point of $F$.

Proof By Theorem 2, $F$ has at least one coupled fixed point with equal components, $(\bar{x}, \bar{x}) \in$ $C \times C$

We first show that the sequence $\left\{x_{n}-F\left(x_{n}, x_{n}\right)\right\}_{n \in \mathbb{N}}$ converges strongly to zero.

We have

$$
\begin{aligned}
\left\|x_{n+1}-\bar{x}\right\|^{2}= & \left\|\lambda x_{n}+(1-\lambda) F\left(x_{n}, x_{n}\right)-\bar{x}\right\|^{2} \\
= & \left\|\lambda\left(x_{n}-\bar{x}\right)+(1-\lambda)\left(F\left(x_{n}, x_{n}\right)-\bar{x}\right)\right\|^{2} \\
= & \lambda^{2} \cdot\left\|x_{n}-\bar{x}\right\|^{2}+(1-\lambda)^{2} \cdot\left\|F\left(x_{n}, x_{n}\right)-\bar{x}\right\|^{2} \\
& +2 \lambda(1-\lambda)\left\langle F\left(x_{n}, x_{n}\right)-\bar{x}, x_{n}-\bar{x}\right\rangle .
\end{aligned}
$$

Similarly,

$$
\left\|x_{n}-F\left(x_{n}, x_{n}\right)\right\|^{2}=\left\|x_{n}-\bar{x}\right\|^{2}+\left\|F\left(x_{n}, x_{n}\right)-\bar{x}\right\|^{2}-2\left\langle F\left(x_{n}, x_{n}\right)-\bar{x}, x_{n}-\bar{x}\right\rangle .
$$

On the other hand, by the weak nonexpansiveness condition $(2.1)$ and $F(\bar{x}, \bar{x})=\bar{x}$, we obtain

$$
\left\|F\left(x_{n}, x_{n}\right)-\bar{x}\right\|=\left\|F\left(x_{n}, x_{n}\right)-F(\bar{x}, \bar{x})\right\| \leq\left\|x_{n}-\bar{x}\right\| .
$$

Now, by (3.2), (3.3), and the inequality above, it follows that for any real number $a$ we have

$$
\begin{aligned}
& \left\|x_{n+1}-\bar{x}\right\|^{2}+a^{2}\left\|x_{n}-F\left(x_{n}, x_{n}\right)\right\|^{2} \\
& \quad \leq\left[2 a^{2}+\lambda^{2}+(1-\lambda)^{2}\right] \cdot\left\|x_{n}-\bar{x}\right\|^{2}+2\left[\lambda(1-\lambda)-a^{2}\right] \cdot\left\langle F\left(x_{n}, x_{n}\right)-\bar{x}, x_{n}-\bar{x}\right\rangle .
\end{aligned}
$$

If we choose now a nonzero $a$ such that $a^{2} \leq \lambda(1-\lambda)$, then from the last inequality we obtain

$$
\begin{aligned}
& \left\|x_{n+1}-\bar{x}\right\|^{2}+a^{2}\left\|x_{n}-F\left(x_{n}, x_{n}\right)\right\|^{2} \\
& \quad \leq\left(2 a^{2}+\lambda^{2}+(1-\lambda)^{2}+2 \lambda(1-\lambda)-2 a^{2}\right)\left\|x_{n}-\bar{x}\right\|^{2}=\left\|x_{n}-\bar{x}\right\|^{2}
\end{aligned}
$$


(we used the Cauchy-Schwarz inequality, $\left\langle F\left(x_{n}, x_{n}\right)-\bar{x}, x_{n}-\bar{x}\right\rangle \leq\left\|F\left(x_{n}, x_{n}\right)-\bar{x}\right\| \cdot\left\|x_{n}-\bar{x}\right\| \leq$ $\left.\left\|x_{n}-\bar{x}\right\|^{2}\right)$. So, by (3.5) we get

$$
a^{2}\left\|x_{n}-F\left(x_{n}, x_{n}\right)\right\|^{2} \leq\left\|x_{n}-\bar{x}\right\|^{2}-\left\|x_{n+1}-\bar{x}\right\|^{2}, \quad n \geq 0 .
$$

By (3.5) we deduce that $\left\{\left\|x_{n}-\bar{x}\right\|\right\}$ is a decreasing sequence of non negative real numbers, hence it is convergent. By the inequality (3.5), we also have

$$
0 \leq\left\|x_{n}-F\left(x_{n}, x_{n}\right)\right\|^{2} \leq \frac{1}{a^{2}}\left(\left\|x_{n}-\bar{x}\right\|^{2}-\left\|x_{n+1}-\bar{x}\right\|^{2}\right), \quad n \geq 0,
$$

from which, by letting $n \rightarrow \infty$, we obtain

$$
\lim _{n \rightarrow \infty}\left\|x_{n}-F\left(x_{n}, x_{n}\right)\right\|=0
$$

This shows that $x_{n}-F\left(x_{n}, x_{n}\right) \rightarrow 0$ (strongly) and so it follows by demicompactness of $F$ that there exist a subsequence $\left\{x_{n_{k}}\right\} \subset C$ and a point $q \in C$ such that

$$
\lim _{k \rightarrow \infty} x_{n_{k}}=q
$$

As $F$ is nonexpansive, it is continuous. This implies

$$
\lim _{k \rightarrow \infty} F\left(x_{n_{k}}, x_{n_{k}}\right)=F(q, q)
$$

By (3.7), $0=\lim _{k \rightarrow \infty}\left(x_{n_{k}}-F\left(x_{n_{k}}, x_{n_{k}}\right)\right)=q-F(q, q)$, which shows that $(q, q)$ is a coupled fixed point of $F$.

Using now the inequality (3.6), with $\bar{x}=q$, we deduce that the sequence of nonnegative real numbers $\left\{\left\|x_{n}-q\right\|\right\}_{n \geq 0}$ is nonincreasing, hence convergent.

Since its subsequence $\left\{\left\|x_{n_{k}}-q\right\|\right\}_{k \geq 0}$ converges to 0 , it follows that the sequence $\left\{\| x_{n}-\right.$ $q \|\}_{n \geq 0}$ itself converges to 0 , that is, the sequence $\left\{\left(x_{n}, x_{n}\right)\right\}$ converges strongly to $(q, q)$, as $n \rightarrow \infty$.

Remark 2 Any nonexpansive bivariate mapping is weakly nonexpansive. Hence, by Theorem 3, we obtain Corollary 2.3 in [22].

We now introduce the concept of demicompactness at a point for a bivariate operator (adapted from the original definition of Petryshyn [34]).

Definition 4 A map $F$ of $C \times C \subset H \times H$ into $H$ is said to be demicompact at $(u, u)$ if, for any bounded sequence $\left\{x_{n}\right\}$ in $C$ such that $x_{n}-F\left(x_{n}, x_{n}\right) \rightarrow(u, u)$ as $n \rightarrow \infty$, there exist a subsequence $\left\{x_{n_{j}}\right\}$ and an $x$ in $C$ such that $x_{n_{j}} \rightarrow x$ as $j \rightarrow \infty$ and $x-F(x, x)=u$.

Remark 3 Clearly, if $F$ is demicompact on $C$, then it is demicompact at 0 but the converse is not true.

The demicompactness of $F$ on the whole $C$ in Theorem 3 may be weakened to the demicompactness at 0 , provided that $F$ is continuous. 
Theorem 4 Let $H$ be a Hilbert space, $C$ a closed, bounded and convex subset of $H$, and $F: C \times C \rightarrow C$ a weakly nonexpansive mapping such that $F$ is demicompact at 0 .

Then the Krasnoselskij-type double sequence $\left\{\left(x_{n}, x_{n}\right)\right\}_{n=0}^{\infty}$ given by $x_{0}$ in $C$ and (3.1) converges (strongly) to a coupled fixed point of $F$.

Proof Note that in the proof of Theorem 3, we actually used the demicompactness of $F$ at 0 , so the arguments used there can be applied here.

Remark 4 The conclusion of Theorem 4 remains true if instead of the demicompactness of $F$ at 0 , we suppose $x \mapsto x-F(x, x)$ maps closed sets in $C$ into closed sets of $H$ (see [34]).

If in Theorems 3 and 4, we remove the demicompactness assumption, then (see [37]), the Krasnoselskij iteration does no longer converge strongly, in general, but it could converge (at least) weakly to a fixed point, as shown in the next theorem, which extends Theorem 3.3 in [37].

Denote by $\operatorname{Fix}(F)$, the set of all coupled fixed points of $F$ with equal components, i.e., $\operatorname{Fix}(F)=\{p \in C: F(p, p)=p\}$.

Theorem 5 Let $H$ be a Hilbert space, $C$ a closed, bounded and convex subset of $H$, and $F$ : $C \times C \rightarrow C$ a weakly nonexpansive mapping such that $\operatorname{Fix}(F)=\{p\}$. Then the Krasnoselskij iteration $\left\{x_{n}\right\}_{n=0}^{\infty}$ given by $x_{0}$ in $C$ and

$$
x_{n+1}=(1-\lambda) x_{n}+\lambda F\left(x_{n}, x_{n}\right), \quad n \geq 0,
$$

converges weakly to $p$, for any $\lambda \in(0,1)$.

Proof It suffices to show that if $\left\{x_{n_{j}}\right\}_{j=0}^{\infty}, x_{n_{j}}=T^{n_{j}} x$, where $T x=\lambda x+(1-\lambda) F(x, x)$, converges weakly to a certain $p_{0}$, then $p_{0}$ is a fixed point of $T$ (and hence $p_{0} \in \operatorname{Fix}(F)$ ) and therefore $p_{0}=p$. Suppose that $\left\{x_{n_{j}}\right\}_{j=0}^{\infty}$ does not converge weakly to $p$. As $F$ is weakly nonexpansive, we have

$$
\begin{aligned}
\|T x-T y\| & \leq \lambda\|x-y\|+(1-\lambda)\|F(x, x)-F(y, y)\| \\
& \leq \lambda\|x-y\|+(1-\lambda)\|x-y\|=\|x-y\|,
\end{aligned}
$$

which shows that $T$ is nonexpansive and hence we get

$$
\begin{aligned}
\left\|x_{n_{j}}-T p_{0}\right\| & \leq\left\|T x_{n_{j}}-T p_{0}\right\|+\left\|x_{n_{j}}-T x_{n_{j}}\right\| \\
& \leq\left\|x_{n_{j}}-p_{0}\right\|+\left\|x_{n_{j}}-T x_{n_{j}}\right\| .
\end{aligned}
$$

Using the arguments in the proof of Theorem 2, it follows

$$
\left\|x_{n_{j}}-T x_{n_{j}}\right\| \rightarrow 0, \quad \text { as } n \rightarrow \infty
$$

and so the last inequality implies that

$$
\lim \sup \left(\left\|x_{n_{j}}-T p_{0}\right\|-\left\|x_{n_{j}}-p_{0}\right\|\right) \leq 0 .
$$


As in the proof of Theorem 2, we have

$$
\begin{aligned}
\left\|x_{n_{j}}-T p_{0}\right\|^{2} & =\left\|\left(x_{n_{j}}-p_{0}\right)+\left(p_{0}-T p_{0}\right)\right\|^{2} \\
& =\left\|x_{n_{j}}-p_{0}\right\|^{2}+\left\|p_{0}-T p_{0}\right\|^{2}+2\left\langle x_{n_{j}}-p_{0}, p_{0}-T p_{0}\right\rangle,
\end{aligned}
$$

which shows, together with $x_{n_{j}} \rightarrow p_{0}($ as $j \rightarrow \infty)$, that

$$
\lim _{n \rightarrow \infty}\left[\left\|x_{n_{j}}-T p_{0}\right\|^{2}-\left\|x_{n_{j}}-p_{0}\right\|^{2}\right]=\left\|p_{0}-T p_{0}\right\|^{2} .
$$

On the other hand, we have

$$
\begin{aligned}
\left\|x_{n_{j}}-T p_{0}\right\|^{2}-\left\|x_{n_{j}}-p_{0}\right\|^{2}= & \left(\left\|x_{n_{j}}-T p_{0}\right\|-\left\|x_{n_{j}}-p_{0}\right\|\right) \\
& \cdot\left(\left\|x_{n_{j}}-T p_{0}\right\|+\left\|x_{n_{j}}-p_{0}\right\|\right) .
\end{aligned}
$$

Since $C$ is bounded, the sequence

$$
\left\{\left\|x_{n_{j}}-T p_{0}\right\|+\left\|x_{n_{j}}-p_{0}\right\|\right\}
$$

is bounded too, and so by (3.9)-(3.11) we get

$$
\left\|p_{0}-T p_{0}\right\| \leq 0, \quad \text { i.e., } T p_{0}=p_{0} \Leftrightarrow p_{0}=F\left(p_{0}, p_{0}\right)=p .
$$

Remark 5 The assumption Fix $(F)=\{p\}$ in Theorem 5 may be removed to obtain the following more general result (similar to Theorem 3.4 in [37]).

Theorem 6 Let $C$ be a bounded, closed and convex subset of a Hilbert space and $F: C \times$ $C \rightarrow C$ be weakly nonexpansive operator. Then the Krasnoselskij algorithm $\left\{x_{n}\right\}_{n=0}^{\infty}$ given by $x_{0}$ in $C$ and

$$
x_{n+1}=(1-\lambda) x_{n}+\lambda F\left(x_{n}, x_{n}\right), \quad n \geq 0,
$$

converges weakly to a coupled fixed point of $F$.

Proof We essentially follow the steps and arguments of the proof of Theorem 3.4 in [37]. For each $p \in \operatorname{Fix}(F) \mathrm{W}$ and each $n$, we have, as in the proof of Theorem 2,

$$
\left\|x_{n+1}-p\right\| \leq\left\|x_{n}-p\right\|,
$$

which shows that the function $g(p)=\lim _{n \rightarrow \infty}\left\|x_{n}-p\right\|$ is well defined and is a lower semicontinuous convex function on the nonempty convex set $\operatorname{Fix}(F)$. Let

$$
d_{0}=\inf \{g(p): p \in \operatorname{Fix}(F)\} .
$$

For each $\varepsilon>0$, the set

$$
E_{\varepsilon}=\left\{y: g(y) \leq d_{0}+\varepsilon\right\}
$$

is closed, convex, and, hence, weakly compact. 
Therefore $\bigcap_{\varepsilon>0} E_{\varepsilon} \neq \emptyset$ (in fact $\bigcap_{\varepsilon>0} E_{\varepsilon}=\left\{y: g(y)=d_{0}\right\} \equiv F_{0}$ ). Moreover, $F_{0}$ contains exactly one point. Indeed, since $F_{0}$ is convex and closed, for $p_{0}, p_{1} \in F_{0}$, and $p_{\lambda}=(1-$ ג) $p_{0}+\lambda p_{1}$

$$
\begin{aligned}
g^{2}\left(p_{\lambda}\right)= & \lim _{n \rightarrow \infty}\left\|p_{\lambda}-x_{n}\right\|^{2}=\lim _{n \rightarrow \infty}\left(\left\|\lambda\left(p_{1}-x_{n}\right)+(1-\lambda)\left(p_{0}-x_{n}\right)\right\|^{2}\right) \\
= & \lim _{n \rightarrow \infty}\left(\lambda^{2}\left\|p_{1}-x_{n}\right\|^{2}+(1-\lambda)^{2}\left\|p_{0}-x_{n}\right\|^{2}+2 \lambda(1-\lambda)\left\langle p_{1}-x_{n}, p_{0}-x_{n}\right\rangle\right) \\
= & \lim _{n \rightarrow \infty}\left(\lambda^{2}\left\|p_{1}-x_{n}\right\|^{2}+(1-\lambda)^{2}\left\|p_{0}-x_{n}\right\|^{2}+2 \lambda(1-\lambda)\left\|p_{1}-x_{n}\right\| \cdot\left\|p_{0}-x_{n}\right\|\right) \\
& +\lim _{n \rightarrow \infty}\left\{2 \lambda(1-\lambda)\left[\left\langle p_{1}-x_{n}, p_{0}-x_{n}\right\rangle-\left\|p_{1}-x_{n}\right\| \cdot\left\|p_{0}-x_{n}\right\|\right]\right\} \\
= & g^{2}(p)+\lim _{n \rightarrow \infty}\left\{2 \lambda(1-\lambda)\left\langle p_{1}-x_{n}, p_{0}-x_{n}\right\rangle-\left\|p_{1}-x_{n}\right\| \cdot\left\|p_{0}-x_{n}\right\|\right\} .
\end{aligned}
$$

Hence

$$
\lim _{n \rightarrow \infty}\left\{2 \lambda(1-\lambda)\left[\left\langle p_{1}-x_{n}, p_{0}-x_{n}\right\rangle-\left\|p_{1}-x_{n}\right\| \cdot\left\|p_{0}-x_{n}\right\|\right]\right\}=0 .
$$

Since

$$
\left\|p_{1}-x_{n}\right\| \rightarrow d_{0} \text { and } \quad\left\|p_{0}-x_{n}\right\| \rightarrow d_{0}
$$

the latter relation implies that

$$
\begin{aligned}
\left\|p_{1}-p_{0}\right\|^{2} & =\left\|\left(p_{1}-x_{n}\right)+\left(x_{n}-p_{0}\right)\right\|^{2} \\
& =\left\|p_{1}-x_{n}\right\|^{2}+\left\|x_{n}-p_{0}\right\|^{2}-2\left\langle p_{1}-x_{n}, p_{0}-x_{n}\right\rangle \\
& \rightarrow d_{0}^{2}+d_{0}^{2}-2 d_{0}^{2}=0,
\end{aligned}
$$

giving a contradiction.

Now, in order to show that $x_{n}=F^{n}\left(x_{0}, x_{0}\right) \rightarrow p_{0}$, it suffices to assume that $x_{n_{j}} \rightarrow p$ for an infinite subsequence and then prove that $p=p_{0}$. By the arguments in the proof of Theorem 3, $p \in \operatorname{Fix}(F)$. Considering the definition of $g$ and the fact that $x_{n_{j}} \rightarrow p$, we have

$$
\begin{aligned}
\left\|x_{n_{j}}-p_{0}\right\|^{2} & =\left\|x_{n_{j}}-p+p-p_{0}\right\|^{2} \\
& =\left\|x_{n_{j}}-p\right\|^{2}+\left\|p-p_{0}\right\|^{2}-2\left\langle x_{n_{j}}-p, p-p_{0}\right\rangle \\
& \rightarrow g^{2}(p)+\left\|p-p_{0}\right\|^{2}=g^{2}\left(p_{0}\right)=d_{0}^{2} .
\end{aligned}
$$

Since $g^{2}(p) \geq d_{0}^{2}$, the last inequality implies that

$$
\left\|p-p_{0}\right\| \leq 0
$$

which means that $p=p_{0}$.

\section{Conclusions and further study}

Example 3 Let $X=\mathbb{R}$ (with the usual metric), $C=[-1,1]$. Define bivariate function $F$ : $C^{2} \rightarrow C$ by

$$
F(x, y)=-\frac{x+y}{2}, \quad \forall x, y \in C .
$$


Then $F$ satisfies (2.1) and is demicompact. Hence, all the assumptions of Theorem 2 are satisfied. It is easy to see that $F$ possesses a unique coupled fixed point, $(0,0)$, and the Krasnoselskij-type iteration algorithm (3.1) yields the sequence

$$
x_{n}=(1-2 \lambda)^{n} x_{0}, \quad n \geq 0 .
$$

Since $-1<1-2 \lambda<1$, it follows that $\left(x_{n}, x_{n}\right)$ converges to $(0,0)$ as $n \rightarrow \infty$, for any initial value $x_{0}$.

This shows that, for weakly nonexpansive mappings, by using a Krasnoselskij-type iteration we can reach the convergence, while, by means of Picard-type iterations, this cannot be obtained, in general. Indeed, in this case, the Picard-type iteration $\left(u_{n}, u_{n}\right)$ associated with $F$ is given by $u_{n+1}=-u_{n}, n \geq 0$, which is not convergent (except for the case $u_{0}=0$ ).

Remark 6 It is important at this stage to say that the coupled fixed point theorems existing in literature, see $[1,4-7,10,13,15-18,23-31]$ (only a short list is cited here), cannot be applied to the bivariate functions in Examples 1 and 3.

Finally, let us note that the double sequence $\left\{\left(x_{n}, y_{n}\right)\right\}$, defined for each component by a formula of the form (3.1) with $F\left(x_{n}, y_{n}\right)$ and $F\left(y_{n}, x_{n}\right)$, respectively, instead of $F\left(x_{n}, x_{n}\right)$, in the case of the function $F$ in Example 1 will be given by

$$
\begin{array}{ll}
x_{n}=\frac{1}{2}\left[(1-\lambda)^{n}\left(x_{0}-y_{0}\right)+(1-2 \lambda)^{n}\left(x_{0}+y_{0}\right)\right], & n \geq 0, \\
y_{n}=\frac{1}{2}\left[(1-\lambda)^{n}\left(y_{0}-x_{0}\right)+(1-2 \lambda)^{n}\left(x_{0}+y_{0}\right)\right], & n \geq 0,
\end{array}
$$

and it is easily seen that $\left\{\left(x_{n}, y_{n}\right)\right\}$ still converges to $(0,0)$, the unique coupled fixed point of $F$, for all $x_{0}, y_{0} \in C$.

This also indicates that it is not necessary to consider only the case of a double sequence with equal components $\left\{\left(x_{n}, x_{n}\right)\right\}$ in Theorems 3-6 (but the proof of a convergence theorem for such an iterative method will be essentially different from the one given in this paper).

To conclude this paper, we note that, for the general case of a weakly nonexpansive bivariate mapping $F$, the Picard-type iteration process (2.4) does not generally converge or, even if it converges, its limit is not a coupled fixed point of $F$, but the Krasnoselskij-type iteration process always converges to a coupled fixed point of $F$.

In the same way, we can prove convergence theorems for iterative methods of Krasnoselskij type for tripled fixed points, quadruple fixed points etc. of weakly nonexpansive mappings (see [8, 9, 11, 14, 19-21, 38-51], and references therein).

Competing interests

The authors declare that they have no competing interests.

Authors' contributions

All authors contributed equally to the writing of this paper. All authors read and approved the final manuscript.

Author details

${ }^{1}$ Department of Mathematics and Computer Science, North University Center at Baia Mare, Technical University of Cluj-Napoca, Victorie 76, Baia Mare, 430072, Romania. ${ }^{2}$ Department of Mathematics and Statistics, King Fahd University of Petroleum and Minerals, Dhahran, Saudi Arabia. ${ }^{3}$ Department of Analysis, Forecast and Mathematics, Faculty of Economics and Bussiness Administration, Babeş-Bolyai University of Cluj-Napoca, 56-60 T. Mihali St., Cluj-Napoca, 400591, Romania. 


\section{Acknowledgements}

The paper has been finalized during the first author's visit of Department of Mathematics and Statistics, King Fahd University of Petroleum and Minerals. He gratefully thanks the host for kind hospitality and excellent work facilities offered. The first and third authors' research was supported by the Grants PN-II-RU-TE-2011-3-239 and

PN-II-ID-PCE-2011-3-0087 of the Romanian Ministry of Education and Research. The second author is grateful to KACST, Riyad, for supporting research project ARP-32-34. We are grateful to the anonymous referee for the extremely careful reading of the first version of this manuscript and for the corresponding suggestions for improvement, and especially for pointing out a few (non-fatal) errors in the proofs.

Received: 12 April 2014 Accepted: 30 June 2014 Published: 22 Jul 2014

\section{References}

1. Bhaskar, TG, Lakshmikantham, V: Fixed point theorems in partially ordered metric spaces and applications. Nonlinear Anal. 65(7), 1379-1393 (2006)

2. Opoitsev, Vl: Nelineinaya sistemostatika. Ekonomiko-Matematicheskaya Biblioteka (Nonlinear Systemostatics. Library of Mathematical Economics), vol. 31. Nauka, Moscow (1986)

3. Abbas, M, Khan, AR, Nazir, T: Coupled common fixed point results in two generalized metric spaces. Appl. Math. Comput. 217, 6328-6336 (2011)

4. Aghajani, A, Arab, R: Fixed points of $(\psi, \varphi, \theta)$-contractive mappings in partially ordered $b$-metric spaces and application to quadratic integral equations. Fixed Point Theory Appl. 2013, 245 (2013). doi:10.1186/1687-1812-2013-245

5. Aghajani, A, Abbas, M, Kallehbasti, EP: Coupled fixed point theorems in partially ordered metric spaces and application. Math. Commun. 17(2), 497-509 (2002)

6. Amini-Harandi, A: Coupled and tripled fixed point theory in partially ordered metric spaces with application to initial value problem. Math. Comput. Model. 57(9-10), 2343-2348 (2013)

7. Aydi, H, Samet, B, Vetro, C: Coupled fixed point results in cone metric spaces for $\tilde{W}$-compatible mappings. Fixed Point Theory Appl. 2011, 27 (2011). doi:10.1186/1687-1812-2011-27

8. Berinde, V: Generalized coupled fixed point theorems for mixed monotone mappings in partially ordered metric spaces. Nonlinear Anal. 74(18), 7347-7355 (2011)

9. Berinde, V: Coupled coincidence point theorems for mixed monotone nonlinear operators. Comput. Math. Appl. 64(6), 1770-1777 (2012)

10. Berinde, V: Coupled fixed point theorems for $\varphi$-contractive mixed monotone mappings in partially ordered metric spaces. Nonlinear Anal. 75(6), 3218-3228 (2012)

11. Berinde, V, Borcut, M: Tripled fixed point theorems for contractive type mappings in partially ordered metric spaces. Nonlinear Anal. 74, 4889-4897 (2011)

12. Berinde, V, Păcurar, M: Coupled fixed point theorems for generalized symmetric Meir-Keeler contractions in ordered metric spaces. Fixed Point Theory Appl. 2012, 115 (2012)

13. Berzig, M, Samet, B: An extension of coupled fixed point's concept in higher dimension and applications. Comput. Math. Appl. 63(8), 1319-1334 (2012)

14. Borcut, M, Berinde, V: Tripled coincidence theorems for contractive type mappings in partially ordered metric spaces. Appl. Math. Comput. 218(10), 5929-5936 (2012)

15. Ćirić, L, Damjanović, B, Jeli, M, Samet, B: Coupled fixed point theorems for generalized Mizoguchi-Takahashi contractions with applications. Fixed Point Theory Appl. 2012, 51 (2012). doi:10.1186/1687-1812-2012-51

16. Ibn Dehaish, BA, Khamsi, MA, Khan, AR: Mann iteration process for asymptotic pointwise nonexpansive mappings in metric spaces. J. Math. Anal. Appl. 397(2), 861-868 (2013)

17. Gu, F, Yin, Y: A new common coupled fixed point theorem in generalized metric space and applications to integral equations. Fixed Point Theory Appl. 2013, 266 (2013). doi:10.1186/1687-1812-2013-266

18. Hussain, N, Salimi, P, Al-Mezel, S: Coupled fixed point results on quasi-Banach spaces with application to a system of integral equations. Fixed Point Theory Appl. 2013, 261 (2013). doi:10.1186/1687-1812-2013-261

19. Karapinar, E, Berinde, V: Quadruple fixed point theorems for nonlinear contractions in partially ordered metric spaces. Banach J. Math. Anal. 6(1), 74-89 (2012)

20. Khan, AR: Common fixed points and solutions of nonlinear functional equations. Fixed Point Theory Appl. 2013, 290 (2013)

21. Khan, AR, Abbas, M, Ali, B: Tripled coincidence and common fixed point theorems for hybrid pair of mappings. Creative Math. Inform. 22(1), 53-64 (2013)

22. Olaoluwa, H, Olaleru, JO, Chang, SS: Coupled fixed point theorems for asymptotically nonexpansive mappings. Fixed Point Theory Appl. 2013, 68 (2013)

23. Sabetghadam, F, Masiha, HP, Sanatpour, AH: Some coupled fixed point theorems in cone metric spaces. Fixed Point Theory Appl. 2009, Article ID 125426 (2009)

24. Samet, B, Vetro, C, Vetro, P: Fixed point theorems for $\alpha-\psi$-contractive type mappings. Nonlinear Anal. 75(4), 2154-2165 (2012)

25. Sang, Y: A class of $\varphi$-concave operators and applications. Fixed Point Theory Appl. 2013, 274 (2013). doi:10.1186/1687-1812-2013-274

26. Shatanawi, W, Samet, B, Abbas, M: Coupled fixed point theorems for mixed monotone mappings in ordered partial metric spaces. Math. Comput. Model. 55(3-4), 680-687 (2012)

27. Sintunavarat, $\mathrm{W}, \mathrm{Kumam}, \mathrm{P}, \mathrm{Cho}, \mathrm{YJ}$ : Coupled fixed point theorems for nonlinear contractions without mixed monotone property. Fixed Point Theory Appl. 2012, 170 (2012). doi:10.1186/1687-1812-2012-170

28. Urs, C: Coupled fixed point theorems and applications to periodic boundary value problems. Miskolc Math. Notes 14(1), 323-333 (2013)

29. $\mathrm{Wu}, \mathrm{J}, \mathrm{Liu}, \mathrm{Y}$ : Fixed point theorems for monotone operators and applications to nonlinear elliptic problems. Fixed Point Theory Appl. 2013, 134 (2013). doi:10.1186/1687-1812-2013-134

30. Xiao, J-Z, Zhu, X-H, Shen, Z-M: Common coupled fixed point results for hybrid nonlinear contractions in metric spaces. Fixed Point Theory 14(1), 235-249 (2013) 
31. Alghamdi, MA, Hussain, N, Salimi, P: Fixed point and coupled fixed point theorems on b-metric-like spaces. J. Inequal. Appl. 2013, 402 (2013). doi:10.1186/1029-242X-2013-402

32. Opoitsev, VI: Dynamics of collective behavior. III. Heterogenic systems. Autom. Remote Control 36(1), 124-138 (1975) (Russian); translated from Avtomat. i Telemeh. 1, 111-124 (1975)

33. Opoitsev, VI, Khurodze, TA: Nelineinye operatory v prostranstvakh s konusom (Russian) (Nonlinear Operators in Spaces with a Cone). Tbilis. Gos. Univ., Tbilisi (1984)

34. Petryshyn, WV: Construction of fixed points of demicompact mappings in Hilbert space. J. Math. Anal. Appl. 14(2), 276-284 (1966)

35. Browder, FE, Petryshyn, WV: Construction of fixed points of nonlinear mappings in Hilbert space. J. Math. Anal. Appl. 20(2), 197-228 (1967)

36. Petryshyn, WV, Williamson, TE Jr.: Strong and weak convergence of the sequence of successive approximations for quasi-nonexpansive mappings. J. Math. Anal. Appl. 43(2), 459-497 (1973)

37. Berinde, V: Iterative Approximation of Fixed Points. Springer, Berlin (2007)

38. Berinde, V, Kovacs, G: Stabilizing discrete dynamical systems by monotone Krasnoselskij type iterative schemes. Creative Math. Inform. 17(3), 298-307 (2008)

39. Chidume, CE: Geometric Properties of Banach Spaces and Nonlinear Iteration. Springer, Berlin (2009)

40. Chidume, CE, Măruşter, Ş: Iterative methods for the computation of fixed points of demicontractive mappings. J. Comput. Appl. Math. 234(3), 861-882 (2010)

41. Krasnoselskij, MA: Two remarks on the method of successive approximations. Usp. Mat. Nauk 10(1(63)), 123-127 (1955) (in Russian)

42. Mann, WR: Mean value methods in iteration. Proc. Am. Math. Soc. 44, 506-510 (1953)

43. Marinescu, DŞ, Monea, M: About Krasnoselskij iterative method. Creative Math. Inform. 22(2), 199-206 (2013)

44. Păcurar, M: Iterative Methods for Fixed Point Approximation. Risoprint, Cluj-Napoca (2010)

45. Păcurar, M: Common fixed points for almost Presić type operators. Carpath. J. Math. 28(1), 117-126 (2012)

46. Rafiq, A, Acu, AM: A new implicit iteration process for two strongly pseudocontractive mappings. Creative Math. Inform. 21(2), 197-201 (2012)

47. Rus, IA: Some properties of the solutions of those equations for which the Krasnoselskii iteration converges. Carpath. J. Math. 28(2), 329-336 (2012)

48. Rus, IA: An abstract point of view on iterative approximation of fixed points. Fixed Point Theory 13(1), 179-192 (2012)

49. Berinde, $\mathrm{V}$ : Convergence theorems for fixed point iterative methods defined as admissible perturbations of a nonlinear operator. Carpath. J. Math. 29(1), 9-18 (2013)

50. Berinde, $V$, Khan, AR, Păcurar, M: Convergence theorems for admissible perturbations of pseudocontractive operators. Miskolc Math. Notes 15(1), 27-37 (2014)

51. Ishikawa, S: Fixed points and iterations of a nonexpansive mapping in a Banach space. Proc. Am. Math. Soc. 59, 65-71 (1976)

10.1186/1687-1812-2014-149

Cite this article as: Berinde et al.: Coupled solutions for a bivariate weakly nonexpansive operator by iterations. Fixed Point Theory and Applications 2014, 2014:149

\section{Submit your manuscript to a SpringerOpen ${ }^{\circ}$ journal and benefit from:}

$\checkmark$ Convenient online submission

Rigorous peer review

- Immediate publication on acceptance

- Open access: articles freely available online

- High visibility within the field

- Retaining the copyright to your article 